\title{
THE DESIGN OF THE ARTERIOVENOUS VASCULAR LOOP DOES NOT AFFECT ITS PATENCY: EXPERIMENTAL STUDY
}

\author{
O FORMATO DA ALÇA VASCULAR NÃO AFETA A \\ PATÊNCIA ARTERIOVENOSA: ESTUDO EXPERIMENTAL
}

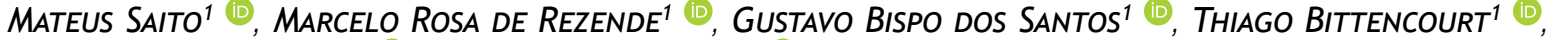 \\ Maria do Carmo Nunes ${ }^{1}{ }^{(0)}$, Rames MatTar Junior ${ }^{1}{ }^{(0)}$
}

1. Universidade de São Paulo, School of Medicine, Institute of Orthopedics and Traumatology, (IOT/FMUSP), Hand and Microsurgery Group, Sao Paulo, SP, Brazil.

\section{ABSTRACT}

Objective: To evaluate the effect of the design of a femoral vascular loop with anastomosis in the femoral artery of rabbits on the presence of flow (patency) after seven days. Methods: A total of 39 rabbits underwent arteriovenous microanastomosis using the microsurgical technique. Two loop designs were used: one circular and the other angled. The parameters evaluated were presence or absence of flow, signs of hemolysis and hemodynamic changes. Results: After seven days, flow was present in $68 \%$ of the angled loops and $75 \%$ of the circular loops $(p>0.05)$. There was a significant intragroup decrease in $\mathrm{pCO}_{2}$ and a significant increase in $\mathrm{pH}$. For the other parameters evaluated, no significant differences between the two loop models were found. Conclusions: A reproducible vascular loop model was shown. There was no significant difference between the two vascular loop models about the presence of flow after seven days. Level of Evidence V, Animal experimental study.

Keywords: Arteriovenous Anastomosis. Vascular Grafting. Femoral Vein.

\section{RESUMO}

Objetivo: Avaliar, em coelhos, qual é a influência do desenho da alça de veia femoral com anastomose na artéria femoral, na presença de fluxo (patência) após sete dias. Método: 39 coelhos foram submetidos à microanastomose arteriovenosa com técnica microcirúrgica. As alças foram acomodadas em dois desenhos, um circular e outro, o mais alongado possível sem dobras na alça. Os parâmetros avaliados foram: presença ou não de fluxo, sinais de hemólise, alterações hemodinâmicas. Resultados: após sete dias, o fluxo estava presente em 68\% das alças anguladas e em $75 \%$ das alças circulares $(p>0,05)$. Houve, intragrupo, diminuição estatisticamente significante da $\mathrm{pCO}_{2}$ e aumento estatisticamente significante do pH. Não houve diferença estatística no restante dos parâmetros avaliados entre os dois modelos de alça. Conclusões: apresentamos um modelo reprodutível de alça vascular. Não houve diferença estatística quanto à presença de fluxo após sete dias nos dois modelos de alça vascular. Nível de Evidência V, Estudo experimental em animais.

Descritores: Anastomose Arteriovenosa. Enxerto Vascular. Veia Femoral.

Citation: Saito M, Rezende MR, Santos GB, Bittencourt T, Nunes MC, Mattar R Jr. The design of the arteriovenous vascular loop does not affect its patency: experimental study. Acta Ortop Bras. [online]. 2020;28(3):121-7. Available from URL: http://www.scielo.br/aob.

\section{INTRODUCTION}

Vascular loops enable the insertion of microsurgical flaps in areas where local recipient vessels are damaged.1,2 These loops have been used in head and neck, as well as trunk and limb, reconstruction. ${ }^{3-9}$ While they can be done during anesthesia for flap transposition, loops can also be prepared days earlier, thereby dividing a long and exhausting procedure into two shorter, more manageable surgeries. ${ }^{10}$
Despite speculation regarding the factors that can lead to its failure, the literature lacks controlled models that demonstrate which of them actually affect the patency of a loop.

The primary objective of this study was to standardize and maintain a vascular loop model in rabbits, thereby determining whether there is a difference in blood flow patency between two different loop designs, "circular" and "angled" (Figure 1).

All authors declare no potential conflict of interest related to this article.

The study was conducted at Universidade de São Paulo, Medical School, Institute of Orthopedics and Traumatology.

Correspondence: Mateus Saito. Rua Dr. Ovídio Pires de Campos, 333, São Paulo, SP, Brazil, 05403-010. msaito@uol.com.br 




Figure 1. Design of loop models. On the left, CIRCULAR model, on the right, ANGLED model.

The secondary objective was to determine the effects of the different loop designs on heart rate, respiratory rate, blood gas analysis and presence of hemolysis.

\section{MATERIALS AND METHODS}

The animals were treated following the "Guide for the Care and Use of Laboratory Animals"10 and the ARRIVE Protocol (Animal Research: Reporting of In Vivo Experiments). ${ }^{11}$

\section{Surgical and Anesthetic Protocol}

Our research involved New Zealand rabbits that were provided by the Central Animal Laboratory of the Medical School, Universidade de São Paulo. Male and female adult rabbits were used based on availability.

The weight of the animals ranged from $2,350 \mathrm{~g}$ to $6,081 \mathrm{~g}$.

The animals were anesthetized with ketamine (40 mg. $\left.\mathrm{kg}^{-1}\right)$ and midazolam (2 mg. $\mathrm{kg}^{-1}$ ), propofol at a $5 \mathrm{mg} / \mathrm{kg}$ dosage and isoflurane diluted in $100 \%$ oxygen by means of the Mapleson D anesthetic circuit.

The animals were prepared for surgery under aseptic conditions; a surgical microscope was used.

Solutions were prepared with $1 \mathrm{ml}$ of $2 \%$ lidocaine to allow vasodilation; a $5000 \mathrm{IU}$ heparin in $10 \mathrm{ml}$ of normal saline was used to prevent thrombus formation in the vessel lumen.

Blood gas, electrolyte, bilirubin and liver enzyme tests were collected from a portion of the femoral artery distal where the anastomosis was performed. An insulin needle was used (0.45 mm x $13 \mathrm{~mm})$.

A medial incision was made in the right thigh, from the inguinal ligament to the knee. The femoral artery and vein were identified from the inguinal ligament to the emergence of the genicular branches (Figure 2). The branches of the femoral vein were ligated, and the vein was detached from its bed. The vein was attached just above the origin of the genicular branches. The distance between the ligature and the point where the vessel crossed the inguinal ligament was measured and noted as the length of the vessel (Figure 3).

An end-to-end anastomosis was performed in the femoral artery immediately after the emergence of the deep femoral artery. A 10-0 mononylon yarn was used with a 75-micrometer needle.



Figure 2. Vascular anatomy of the medial surface of the rabbit's posterior paw.

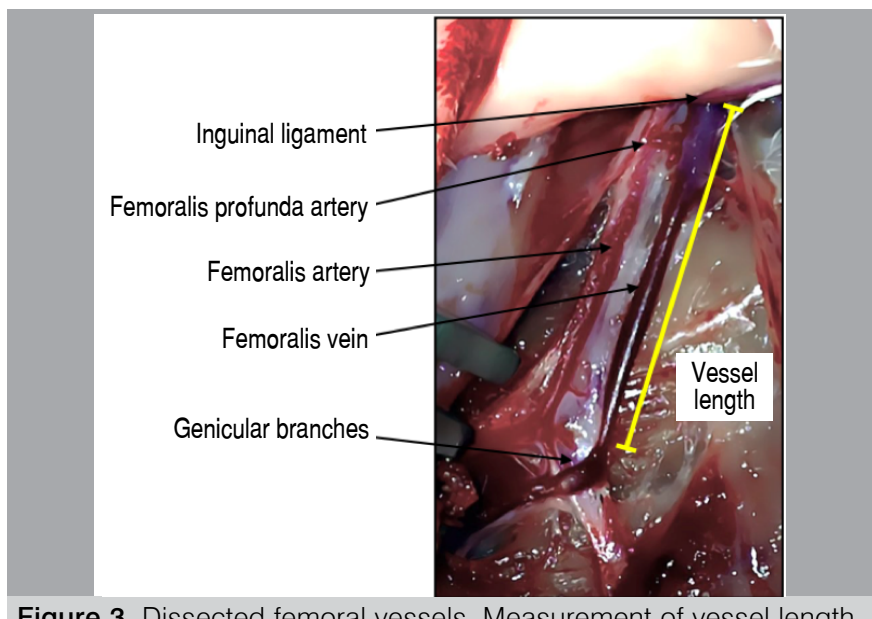

Figure 3. Dissected femoral vessels. Measurement of vessel length, which is used for making the vascular loop.

After completion of the anastomosis (when the loop was positioned), an external collaborator, without direct contact with the procedure, told the surgeon what type of loop to make. This information was generated by a randomization table created on the website www.randomization.com and grouped into permutation blocks ranging from 2, 4 or 6 positions (Figure 4).

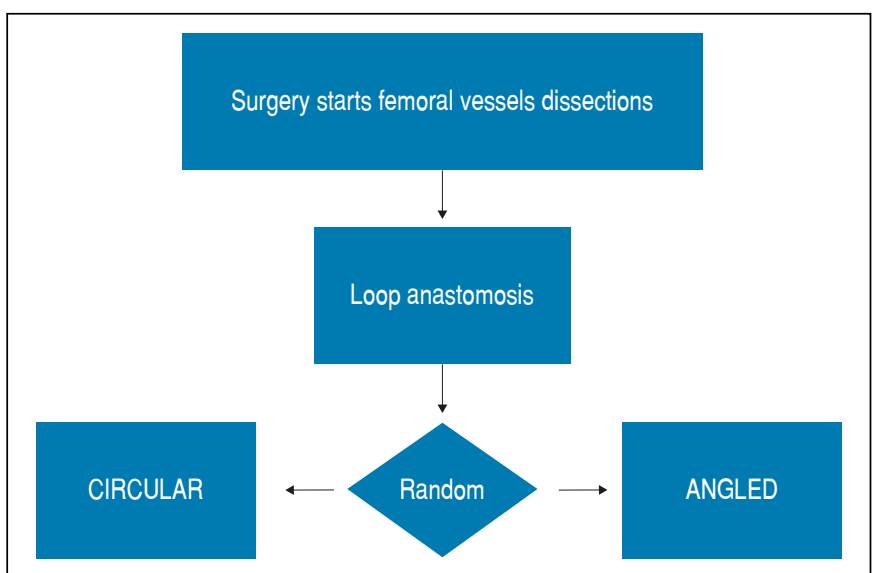

Figure 4. Study design. 
The formed loop was then introduced into one of two possible positions, drawn by lot at the end of the anastomosis, to avoid influencing the surgeon's preference:

a) "ANGLED," folded over itself at the midpoint of its length. The vein was inserted so there would be contact between the descending and ascending sections of the loop, but without constriction of its walls. This shape reaches a more distal region of the foot (Figure 5).

b) "CIRCULAR," introduced to be closer to a circular shape. With a balance between length and width, this loop design reaches a more proximal region of the foot when compared with the "ANGLED" loop positioning (Figure 6).

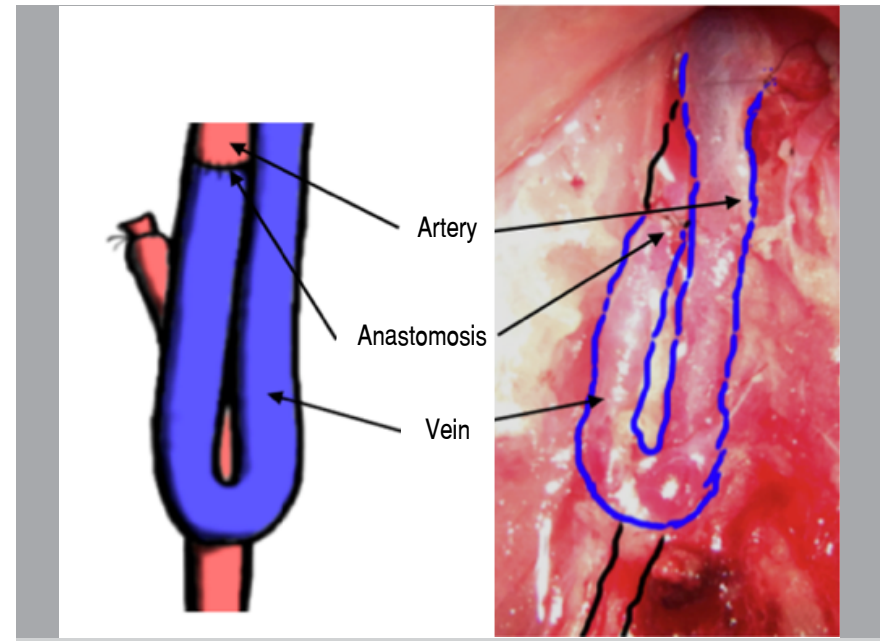

Figure 5. ANGLED loop

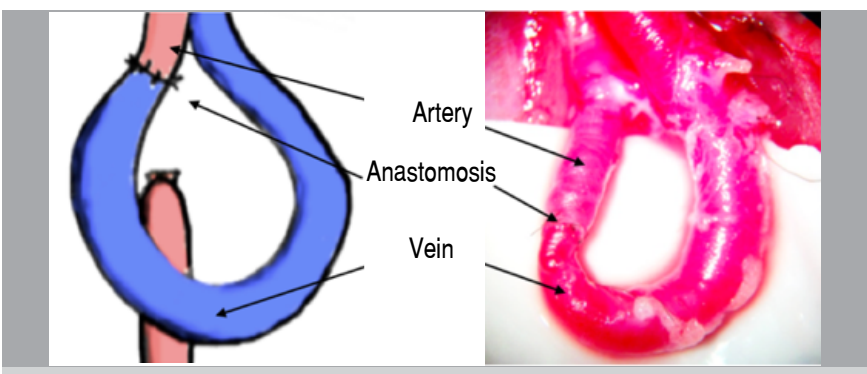

Figure 6. CIRCULAR loop.

The loops were introduced on Bioclusive ${ }^{\circledR}$ sterile plastic film (Johnson \& Johnson, USA), prepared in a rectangular shape, folded back on itself to prevent contact between the adhesive and the tissue, and fixed to the bed with sutures. On this structure, strips made of the same material were attached to the base to keep the loop in the shape required for evaluation.

The loop was measured for length, which was defined as the largest distance from the point where the artery crosses the inguinal ligament, and the largest width perpendicular to the length line. If the loop was "circular," it was measured for its inner diameter, also perpendicular to the length, in the space between the ascending and descending segments of the loop (Figure 7).

After the measurements were taken, another plastic film layer was gently placed on the loop to isolate its environment from the rest of the musculature and prevent the adherence of adjacent tissue. Closure was performed in a plane by plane fashion, attaching the musculature distal to the loop with 4-0 nylon. The subcutaneous plane was closed with inverted sutures and 4-0 nylon.
The skin was closed with 4-0 nylon with separate stitching and a continuous running suture to ensure wound closure.
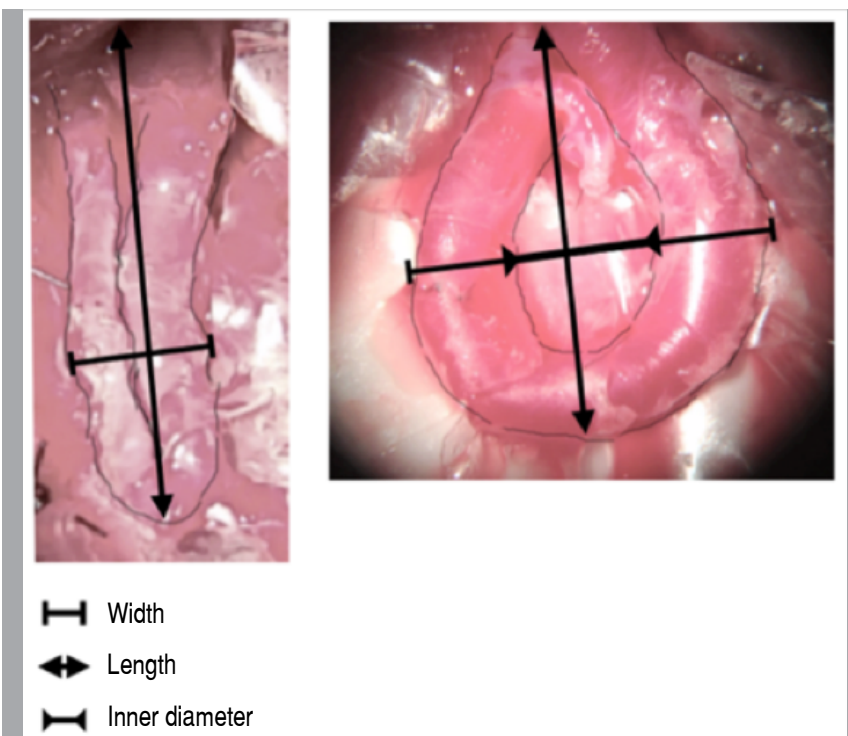

Figure 7. Measurement of the loop dimensions.

The wound was cleaned and coated with antiseptic and repellent spray to discourage licking. A collar was attached to block neck movement but did not disturb the animal's feeding.

The animals were kept in individual cages with food and water available ad libitum; their environment was clean and air-conditioned with a light and dark cycle.

\section{Postoperative}

Following the same protocol, after seven days the animals underwent an additional round of anesthesia for evaluation and subsequent euthanasia.

The loop was identified, the plastic film cut with microsurgery instruments (Figures 8 and 9), then measured, with blood samples taken from a portion of the distal loop for analysis (Table 1). The loop was then sectioned in its distal third, and the flow was evaluated as "present" , when a continuous flow filled the cavity, or "absent", if it was a simple drip. Finally, a dose of 1.0 to $2.0 \mathrm{mEq} / \mathrm{kg}$ potassium chloride was administered.

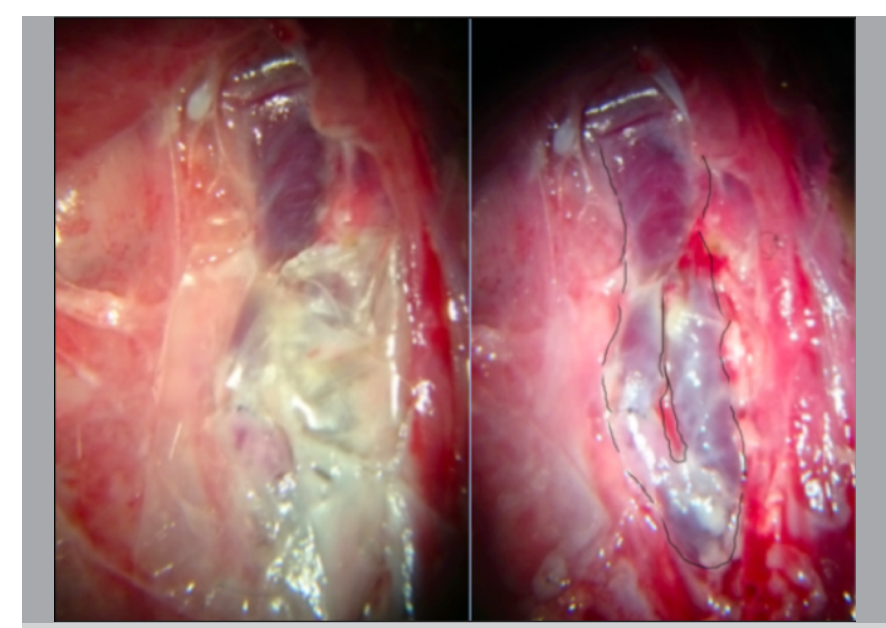

Figure 8. ANGLED vascular loop on the seventh postoperative day (left, still covered in plastic film, right after its removal). 


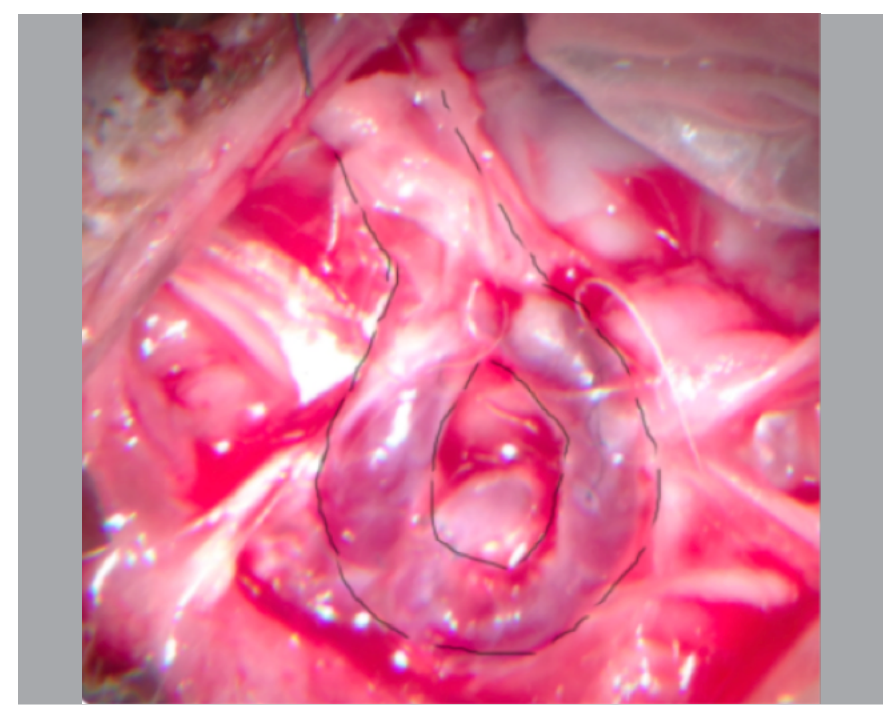

Figure 9. CIRCULAR vascular loop on the seventh postoperative day.

\begin{tabular}{|c|c|c|c|}
\hline \multicolumn{4}{|c|}{ Chi-square tests } \\
\hline & Value & $d f$ & Significance (2-sided) \\
\hline Pearson's chi-square & 0.208 & 1 & 0.648 \\
\hline No. of valid cases & 39 & & \\
\hline
\end{tabular}

\section{Evaluations}

\section{Primary evaluation: patency of the vessels}

The flow was classified as "present" or "absent." In the first 12 specimens, the blood flow was measured using a Transonic T106 Doppler flowmeter (Transonic, Ithaca, NY, USA) (Figure 10).

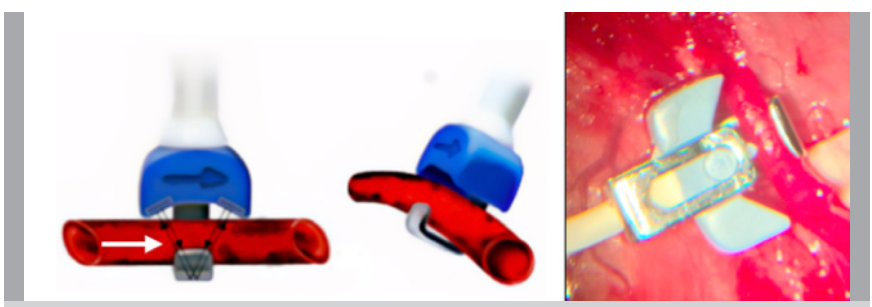

Figure 10. Loop flow evaluation with Doppler flowmeter Transonic T106.

\section{Secondary measures}

Heart rate $(\mathrm{HR})$ and respiratory rate $(\mathrm{RR})$ were measured immediately after the two rounds of anesthesia. HR was measured in beats per minute, allowing the hemodynamic effects of the different vessel types to be evaluated. RR was measured in strokes per minute to evaluate, indirectly, the effectiveness of analgesia and the presence of respiratory depression.

HEMOLYSIS MARKERS: hemoglobin ( $\mathrm{g} / \mathrm{dL}$ ), hematocrit (\%), lactate dehydrogenase $(\mathrm{LDH}, \mathrm{mg} / \mathrm{dl})$ and direct and indirect bilirubin (DB and IB, mg/dL).

BLOOD GAS ANALYSIS: Arterial blood gas levels were collected to evaluate the quality of oxygen supply that the vascular loop could carry for a hypothetical flap to be performed on the seventh postoperative day. Standard blood gas analyses included $\mathrm{pO}_{2}$, $\mathrm{pCO}_{2}, \mathrm{O}_{2}$ saturation, base excess, $\mathrm{pH}, \mathrm{Na}^{+}, \mathrm{K}^{+}, \mathrm{Cl}^{-}$and $\mathrm{Ca}^{2+}$.

\section{RESULTS}

Forty-three surgeries were performed in a controlled and randomized manner. Four specimens died: three during induction of anesthesia and the fourth on the first postoperative day. Information for these four specimens was removed from the data analysis. Data were recorded and analyzed for 39 surgeries.

Twenty-nine rabbits were female, and ten male.

The "circular" loop group comprised 20 specimens, and the "angled" loop group 19

The parameters HR, RR and temperature, measured pre- and post-anesthesia, were similar in both groups.

During sectioning and vessel ligation, the relative percentages of vessel shortening were $26.6 \%$ in the "circular" group and $33.5 \%$ in the "angled" group.

Presence or absence of flow after seven days regarding the vascular loop design (Figures 11 and 12):



Figure 11. Patency of the "ANGLED" loops.

\section{CIRCULAR loops - Patency after 7 days}

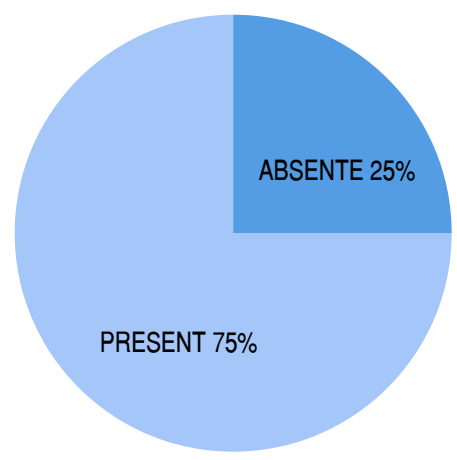

Figure 12. Patency of the "CIRCULAR" loops.

When subjected to statistical analysis using the chi-square test, the comparison between the "angled" and "circular" loop groups showed no significant difference (Table 1).

All blood gas and electrolyte parameters measured showed normal distributions when subjected to the Kolmogorov Smirnov test (Table 2). 
Table 2. Electrolytes and blood gases at the start of surgery.

\begin{tabular}{c|c|c|c|c}
\hline "CIRCULAR" LOOP & Minimum & Maximum & Mean & Standard deviation \\
\hline Initial pH & 7.20 & 7.42 & 7.2616 & 0.07141 \\
\hline Initial pCO $(\mathrm{mmHg})$ & 38.70 & 91.90 & 68.8273 & 17.87032 \\
\hline Initial $\mathrm{pO}_{2}(\mathrm{mmHg})$ & 99.60 & 399.00 & 213.6909 & 94.88694 \\
\hline Initial sat $\mathrm{O}_{2}(\%)$ & 0.00 & 100.60 & 36.3364 & 50.41730 \\
\hline Initial base excess $(\mathrm{mmol} / \mathrm{L})$ & -0.40 & 9.90 & 3.4655 & 3.33866 \\
\hline Initial sodium $(\mathrm{mEq} / \mathrm{L})$ & 137.00 & 148.00 & 140.5455 & 3.17376 \\
\hline Initial potassium $(\mathrm{mEq} / \mathrm{L})$ & 3.10 & 4.60 & 3.7636 & 0.48015 \\
\hline Initial calcium $(\mathrm{mg} / \mathrm{dL})$ & 5.80 & 6.83 & 6.3818 & 0.29144 \\
\hline Initial chloride $(\mathrm{mEq} / \mathrm{L})$ & 96.00 & 116.00 & 104.2727 & 6.03475 \\
\hline "ANGLED" LOOP & Minimum & Maximum & Mean & Standard deviation \\
\hline Initial pH & 7.14 & 7.40 & 7.2812 & 0.07608 \\
\hline Initial pCO $(\mathrm{mmHg})$ & 42.40 & 76.10 & 59.8182 & 11.72449 \\
\hline Initial pO $\mathrm{O}_{2}(\mathrm{mmHg})$ & 40.40 & 400.00 & 236.0727 & 131.00080 \\
\hline Initial sat $\mathrm{O}_{2}(\%)$ & 0.00 & 99.90 & 28.9455 & 41.62591 \\
\hline Initial base excess $(\mathrm{mmo} / \mathrm{L})$ & -0.10 & 6.60 & 2.3609 & 2.22143 \\
\hline Initial sodium $(\mathrm{mEq} / \mathrm{L})$ & 134.00 & 145.00 & 137.7273 & 3.00303 \\
\hline Initial potassium $(\mathrm{mEq} / \mathrm{L})$ & 3.10 & 4.10 & 3.6818 & 0.38423 \\
\hline Initial calcium $(\mathrm{mg} / \mathrm{dL})$ & 6.10 & 6.76 & 6.4255 & 0.19831 \\
\hline Initial chloride $(\mathrm{mEq} / \mathrm{L})$ & 96.00 & 107.00 & 101.5455 & 3.47458 \\
\hline \multicolumn{5}{|c}{}
\end{tabular}

When comparing the initial blood gas and electrolyte values, both the "circular" and "angled" loop groups showed similar baseline values. The laboratory hemolysis markers LDH, total bilirubin (TB), DB and IB measured are listed in Table 3. The concentrations of alanine aminotransferase transaminase (ALT) and aspartate aminotransferase (AST) were measured to rule out hepatopathy concomitant with bilirubin increase, as described in Tables 3 and 4 .

A normal distribution of ALT, AST, and LDH was found. The test rejected the hypothesis of normality for $\mathrm{TB}, \mathrm{DB}$ and $\mathrm{IB}$.

No significant difference was found in any sample in either the intra-group comparison ("circular" or "angled") or the intergroup comparison ("circular" versus "angled") regarding hemolysis tests ( $\mathrm{LDH}, \mathrm{TB}, \mathrm{DB}$ and IB) and transaminases (ALT and AST) was found. Flow, in $\mathrm{mL}^{\mathrm{min}}{ }^{-1}$, was measured in the first 12 specimens (Table 5). The distribution was unusual, with no significant intra- or intergroup differences between initial surgery and euthanasia (Figure 13).

Table 3. Electrolytes and blood gases at euthanasia.

\begin{tabular}{|c|c|c|c|c|}
\hline "CIRCULAR" LOOP & Minimum & Maximum & Mean & Standard deviation \\
\hline Final pH & 7.05 & 7.43 & 7.3092 & 0.10133 \\
\hline Final $\mathrm{pCO}_{2}(\mathrm{mmHg})$ & 10.10 & 66.60 & 46.4909 & 15.00989 \\
\hline Final $\mathrm{pO}_{2}(\mathrm{mmHg})$ & 28.40 & 262.00 & 135.0818 & 88.57413 \\
\hline Final sat $\mathrm{O}_{2}(\%)$ & 35.10 & 101.90 & 80.8875 & 26.79112 \\
\hline Final base excess $(\mathrm{mmol} / \mathrm{L})$ & -6.40 & 4.70 & 0.3455 & 3.81376 \\
\hline Final sodium (mEq/L) & 131.00 & 142.00 & 137.5455 & 3.38714 \\
\hline Final potassium $(\mathrm{mEq} / \mathrm{L})$ & 2.80 & 4.40 & 3.6000 & 0.42661 \\
\hline Final calcium (mg/dL) & 5.51 & 6.74 & 6.1009 & 0.36822 \\
\hline Final chloride (mEq/L) & 94.00 & 116.00 & 103.8182 & 5.65364 \\
\hline "ANGLED" LOOP & Minimum & Maximum & Mean & Standard deviation \\
\hline Final $\mathrm{pH}$ & 7.26 & 7.51 & 7.3584 & 0.07149 \\
\hline Final $\mathrm{pCO}_{2}(\mathrm{mmHg})$ & 27.80 & 55.50 & 48.5111 & 8.82715 \\
\hline Final $\mathrm{pO}_{2}(\mathrm{mmHg})$ & 37.70 & 322.00 & 154.2222 & 115.66063 \\
\hline Final sat $\mathrm{O}_{2}(\%)$ & 53.70 & 101.70 & 86.8000 & 17.34474 \\
\hline Final base excess (mmol/L) & -2.90 & 6.40 & 1.3889 & 3.06938 \\
\hline Final sodium (mEq/L) & 133.00 & 144.00 & 138.5556 & 4.36208 \\
\hline Final potassium (mEq/L) & 0.00 & 4.00 & 3.1800 & 1.15065 \\
\hline Final calcium (mg/dL) & 0.00 & 6.52 & 5.4590 & 1.92931 \\
\hline Final chloride (mEq/L) & 93.00 & 112.00 & 103.6667 & 6.30476 \\
\hline
\end{tabular}

Table 4. Distribution of biochemical hemolysis markers.

\begin{tabular}{|c|c|c|c|c|}
\hline \multicolumn{5}{|c|}{ Circular design } \\
\hline & Minimum & Maximum & Mean & Standard Deviation \\
\hline Initial ALT (IU/L) & 20 & 67 & 36.75 & 14.710 \\
\hline Initial AST (IU/L) & 11 & 37 & 25.25 & 6.811 \\
\hline Initial TB (mg/dL) & 0.0 & 0.1 & 0.017 & 0.0389 \\
\hline Initial DB (mg/dL) & 0.0 & 0.0 & 0.000 & 0.0000 \\
\hline Initial IB (mg/dL) & 0.0 & 0.1 & 0.017 & 0.0389 \\
\hline Initial LDH (IU/L) & 160.7 & 617.8 & 333.825 & 126.8985 \\
\hline Final ALT (IU/L) & 12 & 48 & 30.36 & 11.102 \\
\hline Final AST (IU/L) & 13 & 39 & 22.00 & 8.450 \\
\hline Final TB (mg/dL) & 0.0 & 0.1 & 0.018 & 0.0405 \\
\hline Final DB (mg/dL) & 0.0 & 0.0 & 0.000 & 0.0000 \\
\hline Final IB & 0.0 & 0.1 & 0.018 & 0.0405 \\
\hline Final LDH (IU/L) & 124.2 & 345.2 & 232.973 & 66.7961 \\
\hline \multicolumn{5}{|c|}{ Angled design } \\
\hline & Minimum & Maximum & Mean & Standard Deviation \\
\hline Initial ALT (IU/L) & 17 & 73 & 38.42 & 21.043 \\
\hline Initial AST (IU/L) & 18 & 62 & 30.17 & 12.988 \\
\hline Initial TB (mg/dL) & 0.0 & 0.1 & 0.025 & 0.0452 \\
\hline Initial DB (mg/dL) & 0.0 & 0.0 & 0.000 & 0.0000 \\
\hline Initial IB (mg/dL) & 0.0 & 0.1 & 0.025 & 0.0452 \\
\hline Initial LDH (IU/L) & 89.8 & 542.7 & 274.758 & 124.3742 \\
\hline Final ALT (IU/L) & 11 & 173 & 42.09 & 45.034 \\
\hline Final AST (IU/L) & 11 & 62 & 27.36 & 14.603 \\
\hline Final TB $(\mathrm{mg} / \mathrm{dL})$ & 0.0 & 0.0 & 0.000 & 0.0000 \\
\hline Final DB (mg/dL) & 0.0 & 0.0 & 0.000 & 0.0000 \\
\hline Final IB & 0.0 & 0.0 & 0.000 & 0.0000 \\
\hline Final LDH (IU/L) & 1179 & 480.0 & 237.218 & 121.2778 \\
\hline
\end{tabular}

\begin{tabular}{c|c|c|c|c|c} 
Table 5. Flow measured in $\mathrm{mL} . \mathrm{min}^{-1}$ \\
\hline Design & & Minimum & Maximum & Mean & Standard Deviation \\
\hline "ANGLED" & $\begin{array}{c}\text { Flow at start } \\
\text { of surgery }\end{array}$ & 34 & 156 & 85.33 & 40.215 \\
\cline { 2 - 6 } & $\begin{array}{c}\text { Flow at euthanasia } \\
\left.\text { (mL.min }{ }^{-1}\right)\end{array}$ & 0 & 101 & 42.71 & 39.037 \\
\hline "CIRCULAR" & $\begin{array}{c}\text { Flow at start } \\
\text { of surgery }\end{array}$ & 23 & 170 & 72.46 & 39.928 \\
\cline { 2 - 6 } & $\begin{array}{c}\text { Flow at euthanasia } \\
\left.\text { (mL.min }{ }^{-1}\right)\end{array}$ & 0 & 160 & 44.33 & 50.060 \\
\hline
\end{tabular}


Figure 13. Distribution of initial and final flow in $\mathrm{mL} \mathrm{min}-1$ in the two loop designs

Because of the costly equipment and the absence of additional data for the study, the measurement of flow by Doppler was discontinued.

\section{DISCUSSION}

Arteriovenous vascular loops have been widely used for both reconstruction of limbs and tissue revascularization. ${ }^{12}$ Despite the technique having been described since 1982, ${ }^{1}$ some questions remain unanswered. The purpose of this study is to propose an evaluation model to answer the following question: "What is the effect of the loop design on the presence or absence of flow after seven days?" 
The anesthesia protocol was sufficient to allow the animals to survive procedures of up to four hours. There were four deaths in this series, with undefined cause for the three deaths that occurred during induction. The death on the first postoperative day resulted from heavy intraoperative bleeding.

The saphenous vessels were not used, as the arrangement in humans is different, with two veins and one artery composing the same bundle, since this pattern would make the measurement of flow in a single vessel nonviable.

We chose to use the femoral vein, from the confluence of the genicular veins to the confluence of the deep femoral vein. It was necessary to ligate the muscular branches along the entire path of this vessel. The absence of necrosis in the foot shows that the deep femoral artery is sufficient to supply the limb with blood in the absence of the femoral artery.

Concerning the mold that keeps the loop in position, three questions were answered: the biocompatibility of the material; the minimum vessel compression; and the stability of the material when used in the rabbit's thigh (a site of substantial movement).

Hard molds were tested and discarded for causing vessel compression. Instead, we chose to use flaps of Bioclusive ${ }^{\circledR}$ sterile plastic film (Johnson \& Johnson, USA).

The period of seven days between loop construction and the evaluation of patency was chosen in accordance with several clinical trials that waited the same period to evaluate loop maturation and the patient's clinical stabilization. ${ }^{13-15}$

A sample power statistical study was conducted and showed significantly similar numbers of patent vessels in the "circular" and "angular" loops. The proportions of patent vessels in the "angled" and "circular" loop populations were $55 \%$ and $64 \%$, respectively, thus the sample size calculation, allowing for an alpha error of $5 \%$ and a statistical power of $80 \%$, indicated that 466 specimens would be required for each group, for a total of 932 . This sample size would make the project nonviable from ethical, logistical and economic perspectives.

Upon the study completion, the patency rates for the "angled" and "circular" loops were $68 \%$ and $75 \%$, respectively, which are similar to the success rate of a large clinical series, where flaps made after the loop showed a success rate of $66 \% .{ }^{16}$ However, the values are slightly below the success rate for vascular loops in rats, estimated at $77 \% .^{17}$

The flow measurement results did not reflect differences between the two groups. Perhaps a greater number of studies, such as performed by Asano et al., ${ }^{18}$ can provide different results.

Regarding blood gas analysis, there was a decrease in the $\mathrm{pCO}_{2}$ rate from $68.8 \mathrm{mmHg}$ to $46.5 \mathrm{mmHg}$ in the specimens receiving the "circular" loop. This difference was significant and could be explained by an increase in cardiac output, resulting from decreased peripheral vascular resistance, generating an increased respiratory rate and a decreased $\mathrm{CO}_{2}$ level. However, no significant increases in $\mathrm{HR}$ and $\mathrm{RR}$ were found. This may be explained by an increase in alveolar permeability, which was not measured using this method. In specimens subjected to the "angled" loop construction, a minimal increase in $\mathrm{pH}$ and a slight decrease in $\mathrm{pCO}_{2}$ were observed. These differences were clinically insignificant.
Other electrolyte and blood gas parameters showed no significant differences.

Transaminases, DB, IB and LDH did not change before and after the construction of the loop in either group. Bilirubin may increase in cases of hemolysis or hepatopathy. The lack of increased transaminases reveals the absence of hepatopathy.

The vein's responses about dilation and increased blood flow has been demonstrated in diabetic patients ${ }^{19}$ and experimental studies, ${ }^{20}$ although the responses have not been correlated with the vessel shape.

Much of what is known about clinical and histological changes of arteriovenous anastomoses comes from studies with arteriovenous fistulas. ${ }^{20}$ However, such research cannot be used to study vascular loops as the evaluations are usually performed on repeatedly punctured vessels. Regarding evaluating the effect of fistula design on the presence of flow, our study is the first in the literature to consider the vein.

In studies of the vessels' response to increased pressure regimes, from venous to arterial, the shapes that the vessels assume were not compared. Efforts have been made to keep the vessels in the same conformation and to evaluate the results of other factors, such as drugs inhibiting neointimal proliferation. ${ }^{19}$

Moreover, the saphenous vessels were discarded because the conformation of one artery with two veins full of communications would turn the study of isolated response of one saphenous vein impossible. This study was conducted on small animals. The direct application of these results in clinical practice should be approached carefully for the vessel diameter is much smaller than in humans. Performing the technique on medium-sized animals is a step that may be taken to confirm the current results.

The presented thrombosis rate does not preclude comparison between the loop shapes. The same anastomosis procedure was performed on all animals, and the surgeon was advised of the loop only after the anastomosis was completed, requiring only the positioning of the same in its bed, in the "angled" or "circular "shape. The anesthesia and surgery protocols, as well as the surgical technique for creation of the loop, were simplified to facilitate their reproducibility and use in exploring other gaps in scientific knowledge (such as providing blood flow to flaps or preparation of vascularized composite grafts in reconstructive microsurgery). A major contribution of this study is to start breaking the paradigm that an angled loop has a greater chance of thrombosis than a circular one.

In reconstructive microsurgery this may be the difference between a loop reaching a distal point or less in the limb that needs a microsurgical flap, covering the poorer areas in covering tissue, such as the distal third of the leg and ankle.

\section{CONCLUSION}

In this study, whether the design of the vascular loop was "angled" or "circular" did not affect the presence of flow in the vessel after seven days. The blood gas analysis was minimally affected. This is a suitable and reproductible model of vascular loops.

AUTHORS' CONTRIBUTIONS: Each author contributed individually and significantly to the development of this article: MS: design, intellectual and scientific content, technical procedures, acquisition and interpretation of manuscript writing, critical review and approval of the final version of the manuscript; MRR: orientation, discussion of the study design and manuscript review; GBS: developing the anesthesia protocol; MCN: developing wound isolation techniques and preventing the animal from mobilizing the wound; TB: assisting surgeries, collaborating to the flow monitoring, RMJ: design discussions, manuscript review and institutional support.

\section{REFERENCES}

1. Threlfall GN, Little JM, Cummine J. Free flap transfer: preliminary establishment of an arteriovenous fistula: a case report. Aust N Z J Surg. 1982;52(2):182-4.
2. Giovanoli P, Meyer VE. Use of vein loops in reconstructive procedures. Microsurgery. 1998;18(4):242-5. 
3. Greenwald LL, Comerota AJ, Mitra A, Grosh JD, White JV. Free vascularized tissue transfer for limb salvage in peripheral vascular disease. Ann Vasc Surg. 1990;4(3):244-54.

4. Rechnic M, Edelson RJ, Fosburg RG. Single-anastomosis femoral arteriovenous shunt as recipient vessels for free-flap reconstruction of a massive lumbosacral wound. Plast Reconstr Surg. 1997;99(1):242-4.

5. Depprich RA, Naujoks CD, Meyer U, Kübler NR, Handschel JG. Ateriovenous subclavia-shunt for head and neck reconstruction. Head Face Med. 2008;4:27.

6. Reichenberger MA, Harenberg PS, Pelzer M, Gazyakan E, Ryssel H, Germann G et al. Arteriovenous loops in microsurgical free tissue transfer in reconstruction of central sternal defects. J Thorac Cardiovasc Surg. 2010;140(6):1283-7.

7. Lind B, McCarthy W, Derman G, Jacobs C. Arteriovenous loop grafts for free tissue transfer. Vasc Endovascular Surg. 2012;46(1):30-3.

8. Harry BL, Deleyiannis FW. Posterior trunk reconstruction using an anteromedial thigh free flap and arteriovenous loop. Microsurgery. 2013;33(5):416-7.

9. Masden DL, McClinton MA. Arterial conduits for distal upper extremity bypass. J Hand Surg Am. 2013;38(3):572-7.

10. National Research Council (US). Committee for the Update of the Guide for the Care and Use of Laboratory Animals. Guide for the care and use of laboratory animals. 8th ed. Washington, DC: National Academies Press, 2011.

11. Kilkenny C, Browne W, Cuthill IC, Emerson M, Altman DG; NC3Rs Reporting Guidelines Working Group. Animal research: reporting in vivo experiments: the ARRIVE guidelines. Br J Pharmacol. 2010;160(7):1577-9.
12. Yuan SM, Jing H. A reappraisal of saphenous vein grafting. Ann Saudi Med. 2011;31(1):62-71.

13. Cavadas PC. Arteriovenous vascular loops in free flap reconstruction of the extremities. Plast Reconstr Surg. 2008;121(2):514-20.

14. Atiyeh BS, Khalil IM, Hussein MK, Al Amm CA, Musharafieh RS. Temporary arteriovenous fistula and microsurgical free tissue transfer for reconstruction of complex defects. Plast Reconstr Surg. 2001;108(2):485-8.

15. Sørensen JL, Muchardt O, Reumert T. Temporary arteriovenous shunt prior to free flap transfer. Scand J Plast Reconstr Surg Hand Surg. 1990;24(1):43-6.

16. Lin CH, Mardini S, Lin YT, Yeh JT, Wei FC, Chen HC. Sixty-five clinical cases of free tissue transfer using long arteriovenous fistulas or vein grafts. J Trauma. 2004;56(5):1107-17.

17. Polykandriotis E, Drakotos D, Arkudas A, Pryymachuk G, Rath S, Beier JP, et al. Factors influencing successful outcome in the arteriovenous loop model: a retrospective study of 612 loop operations. J Reconstr Microsurg. 2011;27(1):11-8.

18. Asano Y, Ichioka S, Shibata M, Ando J, Nakatsuka T. Sprouting from arteriovenous shunt vessels with increased blood flow. Med Biol Eng Comput. 2005;43(1):126-30.

19. Aschberg S, Ankarcrona H, Bergstrand O, Björkholm M. Temporary arterio-venous shunts to dilate saphenous crossover graft and maintain graft patency. Acta Chir Scand. 1976;142(8):585-7.

20. Langer S, Heiss C, Paulus N, Bektas N, Mommertz G, Rowinska Z, et al. Functional and structural response of arterialized femoral veins in a rodent $\mathrm{AV}$ fistula model. Nephrol Dial Transplant. 2009;24(7):2201-6. 